\title{
Intimate Partner Violence and Comorbid Mental Health Conditions Among Urban Male Patients
}

\author{
Karin $V$. Rbodes, $M D, M S^{1}$ \\ Debra Houry, MD, MPH \\ Catherine Cerulli, $P b D, J D^{3}$ \\ Helen Straus, MD, MPH \\ Nadine J. Kaslow, PbD ${ }^{5}$ \\ Louise-Anne McNutt, $\mathrm{PbD}^{6}$
}

'Department of Emergency Medicine and The School of Social Policy \& Practice

University of Pennsylvania, Philadelphia,

Pennsylvania

${ }^{2}$ Center for Injury Control, Emory University, Atlanta, Georgia

${ }^{3}$ Laboratory of Interpersonal Violence and Victimization, University of Rochester Medical Center, Rochester, New York

${ }^{4}$ Cook County (John H. Stroger, Jr) Hospital, Chicago, Illinois

${ }^{5}$ Department of Psychiatry and Behavioral Sciences, Emory University, Atlanta, Georgia

${ }^{6}$ Department of Epidemiology and Biostatistics, School of Public Health, University at Albany, SUNY, Albany, New York

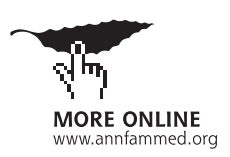

Conflicts of interest: none reported

\section{CORRESPONDING AUTHOR}

Karin Rhodes, MD, MS

Department of Emergency Medicine \&

The School of Social Policy \& Practice

3815 Walnut, Room 201

University of Pennsylvania

Philadelphia, PA 19014

kvr@sp2.upenn.edu

\begin{abstract}
PURPOSE We wanted to explore the associations between intimate partner violence (IPV) and comorbid health conditions, which have received little attention in male patients.
\end{abstract}

METHODS Using a computer-based self-assessment health questionnaire, we screened sequential emergency department patients who were urban, male, and aged 18 to 55 years. We then examined associations between types of IPV disclosures, co-occurring mental health symptoms, and adverse health behaviors.

RESULTS Of 1,669 men seeking nonurgent health care, 1,122 (67.2\%) consented to be screened, and 1,026 (91\%) completed the screening; 712 (63\%) were in a relationship in the past year. Of these men, 261 (37\%) disclosed IPV: 20\% $(n=144)$ disclosed victimization only, $6 \%(n=40)$ disclosed perpetration only, and $11 \%(n=77)$ disclosed bidirectional IPV (defined as both victimization and perpetration in their relationships). Men disclosing both victimization and perpetration had the highest frequencies and levels of adverse mental health symptoms. Rates of smoking, alcohol abuse, and drug use were likewise higher in IPV-involved men.

CONCLUSIONS A cumulative risk of poor mental health and adverse health behaviors was associated with IPV disclosures. Self-disclosure by men seeking acute health care provides the potential for developing tools to assess level of risk and to guide tailored interventions and referrals based on the sex of the patient.

Ann Fam Med 2009;7:47-55. DOI: 10.1370/afm.936.

\section{INTRODUCTION}

Tntimate partner violence (IPV), defined as a pattern of assaultive and coercive behaviors in intimate relationships, remains a major public health concern in the United States. ${ }^{1,2}$ The health care system advocates screening women for victimization and referring them to legal and community-based advocacy services. Both men and women, however, perpetrate a wide range of emotional and physical violence against their intimate partners, and ${ }^{3-5}$ bidirectional IPV may be more common than generally recognized in medical settings. ${ }^{6,7}$ Substance abuse and mental health problems have been found to be major cofactors in IPV, ${ }^{8-10}$ and there is reason to believe that interventions aimed at reducing violent behavior will be only marginally effective if co-occurring mental health and substance abuse problems are ignored. ${ }^{11-15}$ Recent research targeting substance use along with IPV behavior is promising. ${ }^{16-18}$

The US Preventative Service Task Forces ranked the evidence in favor of routine screening for family violence as inconclusive and raised concerns for possible harm from retaliatory IPV after disclosure. Although it is reasonable to consider whether IPV-involved men could benefit from treatment 
under a medical model, the topic requires more study. Numerous studies quantify the co-occurrence of IPV and adverse mental health symptoms and substance use in women patients, ${ }^{19-21}$ but fewer address these issues in IPV-involved men. ${ }^{22}$ In fact, there are few venues for IPV-involved men to receive help outside the criminal justice setting. ${ }^{23}$ The acute health care setting may be one such potential venue. ${ }^{24}$

A recent editorial citing the presence of IPV perpetrators in the emergency department setting called for research on their identification and potential for treatment, ${ }^{25}$ as the emergency department may be the only contact with a health care clinician for low-income and medically underinsured patients. ${ }^{26}$ Previous work suggests both male and female patients will disclose IPV perpetration and victimization on a computer-based health risk assessment in an emergency department setting, knowing the clinician will see the results. ${ }^{27}$ Likewise, MacMillan et $\mathrm{al}^{28}$ found patients preferred self-administered screening.

The larger investigation ascertained the safety and effectiveness of screening urban patients for IPV victimization and perpetration using a computer kiosk ${ }^{29}$ and assessed mental health symptoms in IPV-involved women. ${ }^{30}$ In this article, we focus on the mental health correlates of IPV in male patients. Our second objective was to identify the strength of the associations between types of abuse disclosed (emotional, physical, and sexual, as well as both unidirectional and bidirectional IPV) and the number of co-occurring mental and behavioral health problems in men. We predicted more IPV disclosure in men would be positively associated with an increase in adverse mental health symptoms and substance use.

\section{METHODS}

\section{Study Design}

Our cross-sectional study (with a small prospective follow-up) was made up of primarily African American men seeking care in emergency departments who selfreported being in a relationship in the past year and answered questions about IPV involvement (victimization, perpetration, or both) at a computer kiosk. Four groups of male patients were compared (those disclosing IPV victimization, perpetration, both victimization and perpetration, and those with no IPV disclosures) with respect to mental health symptoms, alcohol use, and use of tobacco and street drugs. All patients who reported IPV received brief counseling and referrals. To assess the safety of the screening process, we collected 1-week and 3-month follow-up information on all victims. At a follow-up interview, which took place in the emergency department, we asked about any adverse events related to screening and whether vic- tims had acted on suggested referrals. Because emergency departments are notorious for poor follow-up rates, we also tracked 911 calls from the addresses of all screened patients living in the surrounding police district for 6 months before and 6 months after the screening visit as a measure of retaliatory violence. ${ }^{29}$

\section{Selection of Participants and Setting}

The study site was in a large southeastern city at a public hospital and trauma center that treats 105,000 patients a year. Sequential eligible patients between the ages of 18 and 55 years were approached in the emergency department waiting room during predetermined study times. Participants were excluded if they could not read English at a 5th-grade level or were intoxicated, acutely psychotic, or too ill to stand and complete a 20-minute health-assessment questionnaire. All participants were taken to a semiprivate booth in the waiting room, where they were invited and, if interested, consented to participate in a study using a computer-based health risk assessment. They received health information and tailored community referrals based on their disclosed health risks. The university institutional review board approved the study.

\section{Data Collection}

We collected standard demographic information and, when possible, used validated questions to measure IPV, depression, traumatic stress, suicidality, and substance use, as well as general health. Participants were free to stop the computer-screening process at any point for any reason, and they were encouraged to stop if they were called to see the physician or became too sick. Any patient who disclosed current suicidality was immediately referred to the attending physician for evaluation.

\section{Methods of Measurement}

IPV victimization and perpetration questions were only asked of patients who said they had been in a relationship in the past year. Victimization was assessed using The George Washington University Universal Violence Prevention Screening Protocol, ${ }^{24}$ which consists of 6 questions previously validated in our population. ${ }^{31}$ To assess perpetration, we used a modified version of a scale developed by the first author ${ }^{32,33}$ that consisted of 8 questions assessing controlling behavior, verbal aggression, attitudes toward physical and sexual aggression, and both physical and sexual abuse of a current partner. The questions and validation information for both IPV scales are available in the Supplemental Appendix, available online at http://www. annfammed.org/cgi/content/full/7/1/47/DC1.

We used the Beck Depression Inventory-II (BDIII $)^{34}$ to ascertain the presence and severity of depres- 
sive symptoms. Total BDI-II scores of 20 or higher, indicative of moderate or severe levels of depressive symptoms, were coded as presence of depressive symptoms. ${ }^{35}$ We used part 3 of the Posttraumatic Stress Diagnostic Scale ${ }^{36}$ to determine the presence and severity of symptoms of posttraumatic stress disorder (PTSD), consistent with recommendations, patients who had scores of 21 or higher, reflective of moderate or severe levels of PTSD symptoms, were coded as having PTSD symptoms. We used the Scale for Suicide Ideation ${ }^{37}$ to measure suicidal intent. Patients scoring 11 or higher were considered positive for suicidal ideation ${ }^{38}$ and were referred for psychiatric evaluation.

Adverse health behaviors related to alcohol abuse were assessed using the CAGE screening test. ${ }^{39}$ One positive response is considered indicative of risky drinking and 2 or more are considered at risk for alcoholism. ${ }^{40,41}$ Because we were also interested in binge drinking, which has a strong association with IPV, 8,16 2 questions were added about quantity and frequency (drinking 3 or more days a week and drinking 4 or more drinks on any single occasion), both of which had to be answered in the affirmative to prompt a concern for possible problem drinking. By contrast, health behaviors related to use of tobacco and street drugs were each assessed by single questions: "Do you smoke cigarettes?" and "Have you used any street drugs in the past 4 weeks?" Because use of tobacco and street drugs was not the focus of the study, these behaviors were not incorporated in the current analysis.

\section{Data Analysis}

We used SAS statistical software (version 8, SAS Institute, Cary, North Carolina) for data analyses. Proportions and a series of $\chi^{2}$ analyses (or exact distribution alternative) were computed to assess bivariate associations between IPV status (any/none) and demographic and health-related characteristics. We used the $t$ test to compare age distributions by IPV status. We calculated prevalence and prevalence ratios of IPV victimization and perpetration status with 95\% confidence intervals to assess bivariate associations between IPV status, mental health symptoms, and health behaviors.

The sample size was calculated from the number of IPV-positive individuals (both men and women) needed for follow-up to assess safety of the IPV screening, about 2 times the number of men needed to assess the association between IPV and mental health reports.

\section{RESULTS}

A total of 1,669 male patients were eligible for participation in the survey, and $1,122(67.2 \%)$ consented to participate. No significant differences existed for race, age, or chief complaint between participants and nonparticipants. Of the men who consented to participate in the study, 1,026 (91\%) participants completed all key elements of the questionnaire. Of the screened men, $712(63 \%)$ participants had been in a relationship in the past year and answered questions about past year victimization or perpetration. This group made up our study population.

Table 1 displays the demographic information of the male participants by their IPV status. Most participants were single, African American, and uninsured. In general, IPV-involved men were less educated and less likely to be employed. They were more likely to be separated or divorced and more likely to report moderate to severe symptoms of depression, PTSD, and suicidality. IPV-involved men also were more likely to engage in other adverse health behaviors, including smoking, at-risk drinking, street drug use, nonuse of seatbelts, and risky sexual behavior.

Table 2 shows the number and percentages of men in relationships and who were positive for IPV victimization and perpetration by each question on the measures. Of the 712 men, 451 (63\%) did not report any IPV, and 261 (37\%) disclosed at least 1 type of IPV (emotional, physical, or sexual): $20 \%(\mathrm{n}=144)$ disclosed IPV victimization only, 5\% $(n=40)$ disclosed IPV perpetration only, and $11 \%(\mathrm{n}=77)$ disclosed bidirectional IPV (both victimization and perpetration). Victimization was reported more often than perpetration, with emotional and physical victimization endorsed more frequently than sexual victimization.

Figure 1 categorizes the mental health symptom scores by the extent of IPV-involvement. Mental health scores in the clinical range (moderate/severe) were more common for those who experienced any IPV and were highest among those reporting both victimization and perpetration; patient reports of any symptoms followed a similar pattern. Table 3 shows the prevalence ratios for both adverse mental health symptoms and unhealthy behaviors by IPV status. Those reporting perpetration only were more likely to report adverse mental health symptoms than those reporting victimization only, but those reporting both victimization and perpetration had the highest levels of adverse mental health symptoms. A similar gradient was identified for adverse health behaviors. The prevalence ratios of drug, tobacco and alcohol use increased as abuse and violence in the relationship increased, with bidirectional IPV having the greatest risks of poor mental health and unhealthy behaviors.

There were no detectable adverse events related to screening, either observed by the research assistants in the emergency department or reported by the 80 (56\%) of male victims who returned for 1 -week follow-up. Nor 


\begin{tabular}{|c|c|c|c|c|c|}
\hline $\begin{array}{l}\text { Characteristic } \\
\text { (No. Responding) }\end{array}$ & $\begin{array}{l}\text { IPV Po } \\
(\mathrm{n}=2\end{array}$ & $\begin{array}{l}\text { itive } \\
51)\end{array}$ & $\begin{array}{l}\text { IPV Nec } \\
\quad(\mathrm{n}=\mathrm{C}\end{array}$ & $\begin{array}{l}\text { ative } \\
\text { 1) }\end{array}$ & $\begin{array}{c}P \\
\text { Value }\end{array}$ \\
\hline \multirow[t]{2}{*}{ Age, mean (range), y $(n=708)$} & \multicolumn{2}{|c|}{$35.4(18-65)$} & \multicolumn{2}{|c|}{$35.2(18-66)$} & .835 \\
\hline & No. & $\%$ & No. & $\%$ & \\
\hline Race $(n=712)$ & & & & & .693 \\
\hline White & $24 / 261$ & 9.2 & $35 / 451$ & 7.8 & \\
\hline African American & $229 / 261$ & 87.7 & $408 / 451$ & 90.5 & \\
\hline Hispanic & $1 / 261$ & 0.4 & $2 / 451$ & 0.4 & \\
\hline Asian & $1 / 261$ & 0.4 & $1 / 451$ & 0.2 & \\
\hline Other & $6 / 261$ & 2.3 & $5 / 451$ & 1.1 & \\
\hline Education $(n=705)$ & & & & & .004 \\
\hline No high school diploma & $52 / 255$ & 20.4 & $60 / 450$ & 13.3 & \\
\hline High school diploma & $128 / 255$ & 50.2 & $201 / 450$ & 44.7 & \\
\hline Some/completed college & $54 / 255$ & 21.2 & $127 / 450$ & 28.2 & \\
\hline College graduate & $21 / 255$ & 8.2 & $62 / 450$ & 13.8 & \\
\hline Health insurance $(n=694)$ & & & & & .126 \\
\hline None & $204 / 253$ & 80.6 & $353 / 441$ & 80.1 & \\
\hline Medicaid/Medicare & $23 / 253$ & 9.1 & $26 / 441$ & 5.9 & \\
\hline Private/employment/student & $26 / 253$ & 10.3 & $62 / 441$ & 14.1 & \\
\hline Marital status $(n=708)$ & & & & & .017 \\
\hline Single (never married) & $176 / 258$ & 68.2 & $325 / 450$ & 72.2 & \\
\hline Separated/divorced/widowed & $53 / 258$ & 20.5 & $58 / 450$ & 12.9 & \\
\hline Married & $29 / 258$ & 11.2 & $67 / 450$ & 14.9 & \\
\hline Reason for visit ( $n=698)$ & & & & & .590 \\
\hline Medical & $215 / 255$ & 84.3 & $365 / 443$ & 82.4 & \\
\hline Injury & $21 / 255$ & 8.2 & $47 / 443$ & 10.6 & \\
\hline Other & $19 / 255$ & 7.5 & $31 / 443$ & 7.0 & \\
\hline Employed $(n=709)$ & $139 / 260$ & 53.5 & $270 / 449$ & 60.1 & .083 \\
\hline $\begin{array}{l}\text { Moderate/severe depression }{ }^{\mathrm{a}} \\
(\mathrm{n}=712)\end{array}$ & $48 / 261$ & 18.4 & $15 / 451$ & 3.3 & $<.001$ \\
\hline Moderate/severe PTSD ${ }^{b}(n=712)$ & $27 / 261$ & 10.3 & $5 / 451$ & 1.1 & $<.001$ \\
\hline Suicidal ideations ${ }^{`}(\mathrm{n}=712)$ & $24 / 261$ & 9.2 & $3 / 451$ & 0.7 & $<.001$ \\
\hline Smoking $(n=712)$ & $163 / 261$ & 62.5 & $224 / 451$ & 49.7 & .001 \\
\hline Street drugs $^{d}(n=712)$ & $90 / 261$ & 34.5 & $110 / 451$ & 24.4 & .004 \\
\hline $\begin{array}{l}\text { High-risk sexual behaviore } \\
(\mathrm{n}=698)\end{array}$ & $95 / 252$ & 37.7 & $118 / 437$ & 27.0 & .003 \\
\hline At-risk drinking ${ }^{\dagger}(n=712)$ & $128 / 261$ & 49.0 & $168 / 451$ & 37.3 & .002 \\
\hline Same-sex sexual partnerg $(n=704)$ & $27 / 259$ & 10.4 & $43 / 445$ & 9.7 & .745 \\
\hline Handgun access $(n=706)$ & $49 / 260$ & 18.9 & $68 / 446$ & 15.3 & .215 \\
\hline Seatbelt use $(n=703)$ & $151 / 258$ & 58.5 & $338 / 445$ & 76.0 & $<.001$ \\
\hline Smoke detectorj $(n=694)$ & $217 / 252$ & 86.1 & $395 / 442$ & 89.4 & .201 \\
\hline
\end{tabular}

$\mathrm{IPV}=$ intimate partner violence; PTSD = posttraumatic stress disorder.

Note: data are reported for the number and percentage of participants answering the particular question or set of questions, (eg, age is missing for 4 participants (3 IPV positive, 1 IPV negative), so $n=708$.

a Depression measured by the Beck Depression Index: scores $\geq 20$ are indicative of moderate or severe levels of depressive symptoms. ${ }^{34,35}$

${ }^{b}$ Posttraumatic Stress Diagnostic Scale: scores $>20$ reflect moderate or severe levels of PTSD symptoms. ${ }^{36}$ ' $S c a l e$ for Suicide Ideation: scores $>11$ were considered suicidal and referred for psychiatric evaluation. ${ }^{37,38}$ ${ }^{\mathrm{d}}$ Use of street drugs in last 4 weeks, or a history of intravenous drug use.

e Nonuse of condoms and 1 of the following: history of a sexually transmitted disease in past 5 years, or more than 1 sexual partner in last year.

${ }^{\mathrm{f}}$ At least 1 positive responses to CAGE questions or drinking at least 3 times week and 4 or more drinks per day on occasion.

${ }^{9} \mathrm{Had}$ sex with a person of the same sex in past 10 years.

${ }^{\mathrm{h}}$ Has handgun in home or car or someone close has a gun.

Always uses a seatbelt in a car.

j Has a working smoke detector where they live. did we identify any increase in 911 calls to the addresses of screened men, regardless of IPV status (Table 4).

For the men disclosing victimization who returned to the emergency department for follow-up visits, Table 5 shows 1 week and 3-month use of referral resources. At 1 week, 55\% said they had read the educational and referral information provided, and $13 \%$ had contacted IPV resources. Although only 47 male victims returned at 3 months, 15 (32\%) reported they had contacted the referral resources $;$ of those, $8(17 \%)$ had sought mental health counseling, and $5(11 \%)$ had sought alcohol counseling.

\section{DISCUSSION}

We found that men coming to an urban emergency department for nonurgent complaints selfdisclosed a substantial amount of IPV, $37 \%$ of men in an intimate relationship in the past year disclosed IPV victimization, perpetration, or both. Results regarding confounding factors, such as social disadvantage, support a general pattern of cumulative exposure leading to increased risk. ${ }^{42-44}$ The amount of IPV involvement was associated with increasing proportions of patients reporting moderate/severe mental health symptoms. Depression, PTSD, and suicidality scores all were higher, and those experiencing and/or perpetrating more types of abuse had the highest number of adverse mental health symptoms. Proportions of smoking, drinking and street drug use were also higher in IPV-involved men, providing further support that at least some of the adverse health effects associated with violence may be due to unhealthy behaviors. ${ }^{45}$ This finding is similar to that of other studies which 


\begin{tabular}{|c|c|}
\hline IPV Questions & No. (\%) \\
\hline \multicolumn{2}{|l|}{ Victimization } \\
\hline $\begin{array}{l}\text { Within the past year has a partner slapped, kicked, pushed, choked, } \\
\text { or punched you? }\end{array}$ & $119(16.7)$ \\
\hline Within the past year has a partner forced or coerced you to have sex? & $48(6.7)$ \\
\hline $\begin{array}{l}\text { Within the past year has a partner threatened you with a knife/gun to } \\
\text { scare/hurt you? }\end{array}$ & $40(5.6)$ \\
\hline $\begin{array}{l}\text { Within the past year has a partner made you afraid you would be } \\
\text { physically hurt? }\end{array}$ & $33(4.6)$ \\
\hline $\begin{array}{l}\text { Within the past year has a partner used words/yelled/screamed in a way } \\
\text { that frightened you? }\end{array}$ & $133(18.7)$ \\
\hline Total disclosing any IPV victimization & $221(31.0)$ \\
\hline \multicolumn{2}{|l|}{ Perpetration } \\
\hline Do you feel like you always need to be in control of your partner? & $61(8.5)$ \\
\hline When you get angry, does it make your partner afraid? & $110(15.5)$ \\
\hline Have you hit/pushed/shoved your partner in the past year? & $86(12.1)$ \\
\hline Do you think there are times when it's OK to physically hurt your partner? & $20(2.8)$ \\
\hline Have you physically hurt your partner in the past year? & $30(4.2)$ \\
\hline Are you worried you might physically hurt your partner? & $34(4.8)$ \\
\hline Do you think your partner should have sex when he/she doesn't want to? & $119(16.7)$ \\
\hline Have you made your partner have sex when he/she didn't want to? & $33(4.6)$ \\
\hline Total disclosing any IPV perpetration & $117(16.4)$ \\
\hline Total disclosing both victimization and perpetration & $77(10.8)$ \\
\hline Total with any IPV & $261(36.7)$ \\
\hline
\end{tabular}

The literature on screening men in health care settings as part of comprehensive health risk assessments is scant, however. Several studies report that men screened in the emergency department for partner violence had rates of partner violence similar to that of women; between $13 \%$ and $30 \%$ of men in various emergency department samples report current physical IPV victimization. ${ }^{52-54}$ Others have concluded that many of these men were abusers. ${ }^{55-57}$ Among men in a batterer's treatment program, $46 \%$ said they had seen a physician in the last 6 months; the emergency department was the most common site. ${ }^{58}$ Because the emergency department is likely to see a heterogeneous group of men with varying levels of IPV risk it will be important to identify men's IPV victimization as well as their perpetration, along with comorbid conditions that might lend themselves to intervention.

found multiple comorbid health conditions in patients with high trauma exposure. ${ }^{45-49}$

There are studies on the psychological comorbidities of men in court-mandated batterer's treatment. ${ }^{10,15}$ Our work lends support to studies that describe the co-occurrence of IPV with depression and substance abuse in IPV-involved individuals. ${ }^{50}$

El-Bassel et al described rates of IPV and substance abuse in women of ethnic minorities, ${ }^{51}$ and others have assessed the mental health impact of IPV in women, ${ }^{18,20,21}$ but less attention has focused on the mental health symptoms and substance abuse problems of IPV-involved men coming to health care settings.

Looking specifically at emergency department patients, Lipsky et al found $15 \%$ of male patients in a Los Angeles emergency department self-reported current IPV perpetration, including $17.1 \%$ of African American and $9.1 \%$ of Latino male patients. ${ }^{52}$ In our study, the cumulative amount of abuse disclosures (emotional, physical, sexual) and amount of unidirectional and bidirectional violence (victimization, perpetration, or both) were related in a dose-response manner to levels of depression, PTSD, and suicidal ideation.

Given the high degree of overlap, one could argue that identifying male partner violence should be a part of any mental health and substance abuse assessment.
Most assessments and interventions with IPVinvolved men have been through the criminal justice system, which uses a one-size-fits-all model of group didactics and cognitive restructuring. ${ }^{59}$ Only a small fraction of IPV-involved men engage in treatment, however, and less than one-half subsequently complete these programs. ${ }^{60,61}$ Not surprisingly, many interventions for IPV-involved men have been unable to show any effectiveness. ${ }^{62,63}$ In part, this lack of effectiveness may be because current interventions for IPV have often failed to address adequately the comorbid mental health and substance abuse problems that may exist for both victims and perpetrators. One central problem in the field of IPV batterer's treatment is how to best match types of interventions to subpopulations of perpetrators. ${ }^{64} \mathrm{New}$ methods for identification and risk stratification of IPV need to account for the severity and periodicity of occurrences, as well as comorbid conditions. If it can be determined that routine IPV screening with men in health care settings is safe, we can add additional tools to improve recognition of high-risk situations and make distinctions between broad categories of male partner violence. Improving our understanding of the interactions between mental health and violence as they relate to the complexities of human relationships will be important if we are to 


\section{Figure 1. Mental health symptom scores, by intimate partner violence status.}

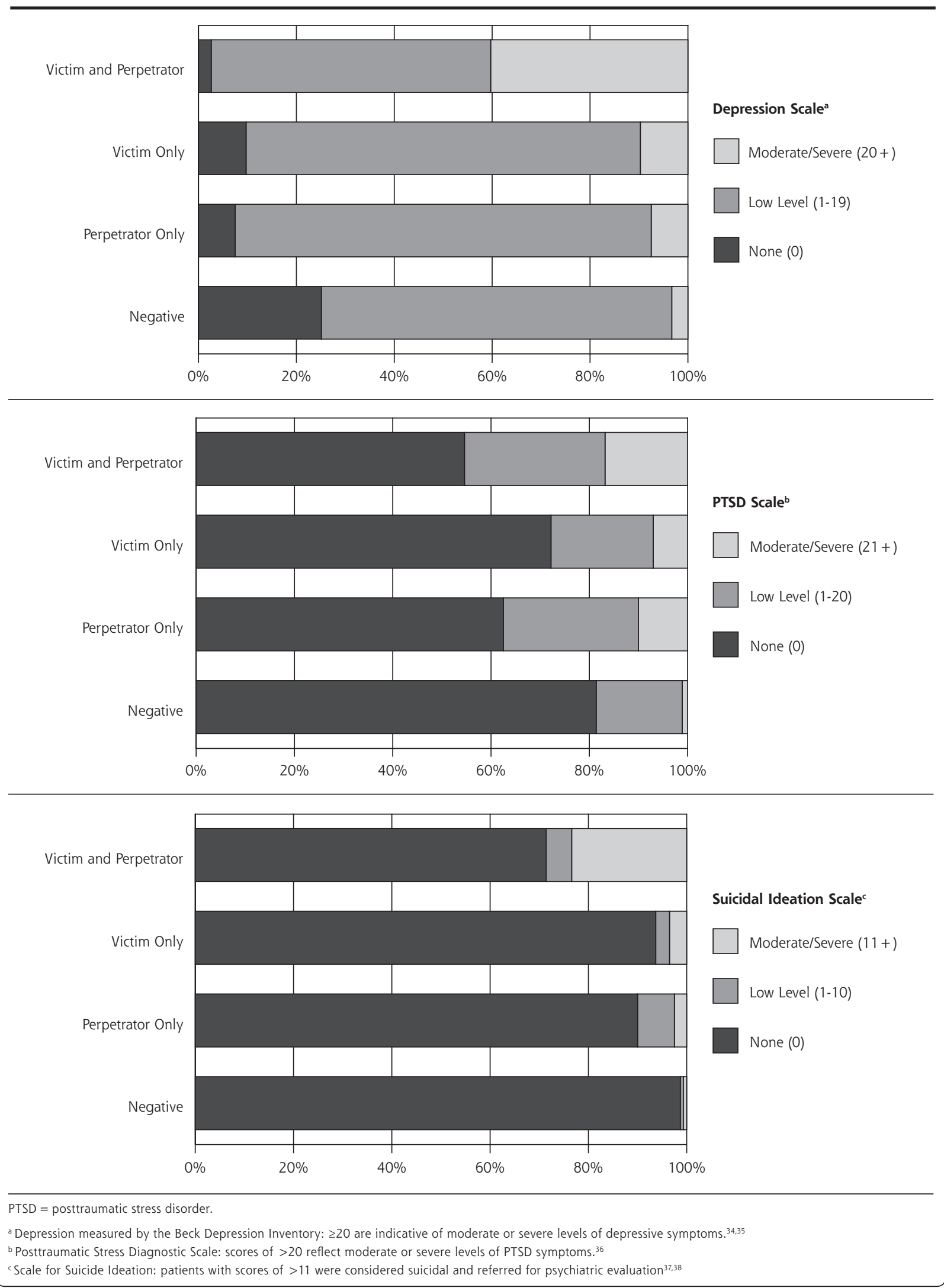




\begin{tabular}{|c|c|c|c|c|c|c|c|c|c|c|}
\hline \multirow{2}{*}{$\begin{array}{l}\text { Symptoms } \\
\text { and Adverse } \\
\text { Behaviors }\end{array}$} & \multicolumn{2}{|c|}{$\begin{array}{l}\text { IPV Negative } \\
\quad(n=451)\end{array}$} & \multicolumn{2}{|c|}{$\begin{array}{l}\text { Any IPV } \\
(n=261)\end{array}$} & \multicolumn{2}{|c|}{$\begin{array}{l}\text { Victim Only } \\
(n=144)\end{array}$} & \multicolumn{2}{|c|}{$\begin{array}{c}\text { Perpetrator } \\
\text { Only } \\
(n=40)\end{array}$} & \multicolumn{2}{|c|}{$\begin{array}{c}\text { Victim and } \\
\text { Perpetrator } \\
(\mathbf{n}=77)\end{array}$} \\
\hline & $\%$ & $\mathrm{PR}^{\mathrm{a}}$ & $\%$ & PR $(95 \% \mathrm{Cl})$ & $\%$ & PR (95\% Cl) & $\%$ & PR $(95 \% \mathrm{Cl})$ & $\%$ & PR $(95 \% \mathrm{Cl})$ \\
\hline Depression & 3.3 & 1.00 & 18.4 & $\begin{array}{c}5.53 \\
(3.16-9.67)\end{array}$ & 9.7 & $\begin{array}{c}2.92 \\
(1.45-5.91)\end{array}$ & 7.5 & $\begin{array}{c}2.26 \\
(0.68-7.46)\end{array}$ & 40.3 & $\begin{array}{c}12.10 \\
(6.87-21.34)\end{array}$ \\
\hline PTSD & 1.1 & 1.00 & 10.3 & $\begin{array}{c}9.33 \\
(3.64-23.93)\end{array}$ & 6.9 & $\begin{array}{c}6.26 \\
(2.18-18.03)\end{array}$ & 10.0 & $\begin{array}{c}9.02 \\
(2.52-32.26)\end{array}$ & 16.9 & $\begin{array}{c}15.23 \\
(5.59-41.51)\end{array}$ \\
\hline Suicidality & 0.7 & 1.00 & 9.2 & $\begin{array}{c}13.82 \\
(4.20-45.46)\end{array}$ & 3.5 & $\begin{array}{c}5.22 \\
(1.26-21.57)\end{array}$ & 2.5 & $\begin{array}{c}5.22 \\
(1.26-21.57)\end{array}$ & 23.4 & $\begin{array}{c}35.14 \\
(10.60-116.46)\end{array}$ \\
\hline Illegal drugs & 24.4 & 1.00 & 34.5 & $\begin{array}{c}1.14 \\
(1.12-1.79)\end{array}$ & 27.1 & $\begin{array}{c}1.11 \\
(0.82-1.52)\end{array}$ & 35.0 & $\begin{array}{c}1.44 \\
(0.91-2.26)\end{array}$ & 48.1 & $\begin{array}{c}1.97 \\
(1.48-2.62)\end{array}$ \\
\hline $\begin{array}{l}\text { Smoke } \\
\text { cigarettes }\end{array}$ & 49.7 & 1.00 & 62.5 & $\begin{array}{c}1.26 \\
(1.10-1.44)\end{array}$ & 64.6 & $\begin{array}{c}1.30 \\
(1.12-1.51)\end{array}$ & 55.0 & $\begin{array}{c}1.11 \\
(0.82-1.49)\end{array}$ & 62.3 & $\begin{array}{c}1.26 \\
(1.03-1.53)\end{array}$ \\
\hline $\begin{array}{l}\text { Ethanol use } \\
\text { in excess }\end{array}$ & 37.3 & 1.00 & 49.0 & $\begin{array}{c}1.32 \\
(1.11-1.56)\end{array}$ & 38.9 & $\begin{array}{c}1.04 \\
(0.82-1.32)\end{array}$ & 50.0 & $\begin{array}{c}1.34 \\
(0.96-1.87)\end{array}$ & 67.5 & $\begin{array}{c}1.81 \\
(1.49-2.21)\end{array}$ \\
\hline
\end{tabular}

\begin{tabular}{|c|c|c|c|c|}
\hline \multirow[b]{2}{*}{ Participants } & \multicolumn{2}{|c|}{$\begin{array}{l}\text { Possible } \\
\text { Violence }\end{array}$} & \multicolumn{2}{|c|}{$\begin{array}{c}\text { Total } \\
\text { Telephone } \\
\text { Calls }\end{array}$} \\
\hline & No. & $\%$ & No. & $\%$ \\
\hline \multicolumn{5}{|c|}{ All participants $(n=531)$} \\
\hline 6 Months before & 67 & 13 & 124 & 23 \\
\hline 6 Months after & 67 & 13 & 143 & 27 \\
\hline \multicolumn{5}{|c|}{$\begin{array}{l}\text { Participant not a victim of IPV } \\
(\mathrm{n}=439)\end{array}$} \\
\hline 6 Months before & 54 & 12 & 99 & 23 \\
\hline 6 Months after & 62 & 14 & 125 & 29 \\
\hline \multicolumn{5}{|c|}{ All IPV victims ( $n=92)$} \\
\hline 6 Months before & 13 & 14 & 25 & 27 \\
\hline 6 Months after & 5 & 5 & 18 & 20 \\
\hline \multicolumn{5}{|c|}{$\begin{array}{l}\text { IPV victim did not participate } \\
\text { in } 1 \text {-week follow-up }(n=51)\end{array}$} \\
\hline 6 Months before & 7 & 14 & 13 & 25 \\
\hline 6 Months after & 3 & 6 & 10 & 20 \\
\hline \multicolumn{5}{|c|}{$\begin{array}{l}\text { IPV victim participated in } \\
\text { 1-week follow-up }(n=41)\end{array}$} \\
\hline 6 Months before & 6 & 15 & 12 & 30 \\
\hline 6 Months after & 2 & 5 & 8 & 20 \\
\hline
\end{tabular}

develop new tailored interventions that can be delivered outside of the criminal justice system. ${ }^{65}$

\section{Limitations}

This study has a number of important limitations. The patient population was a fairly homogeneous convenience sample of urban, primarily indigent, African American men seeking health care at 1 large county
Table 5. Most Frequently Reported Use of Resources and Safety Measures Taken by Male Patients Who Screened Positive for IPV Victimization

\begin{tabular}{|c|c|c|}
\hline $\begin{array}{l}\text { Resources and } \\
\text { Safety Measures }\end{array}$ & $\begin{array}{c}\text { 1-Week } \\
\text { Follow-Up } \\
\text { Report } \\
(n=80) \\
\text { No. }(\%)\end{array}$ & $\begin{array}{c}\text { 3-Month } \\
\text { Follow-Up } \\
\text { Report } \\
(n=47) \\
\text { No. (\%) }\end{array}$ \\
\hline Used any of the resources & $8(10)$ & $15(32)$ \\
\hline Hotline & $2(2.5)$ & $7(15)$ \\
\hline IPV support groups & & $5(11)$ \\
\hline IPV shelter & $1(1.3)$ & $2(4.3)$ \\
\hline Emergency housing & $1(1.3)$ & \\
\hline Alcohol treatment & $1(1.3)$ & $5(11)$ \\
\hline Mental health counseling & $2(2.5)$ & $8(17)$ \\
\hline Read information & $44(55)$ & $24(51)$ \\
\hline Made a safety plan & $13(16)$ & \\
\hline $\begin{array}{l}\text { Hid money in case you need } \\
\text { to leave }\end{array}$ & $15(19)$ & \\
\hline Moved out & $11(14)$ & $18(38)$ \\
\hline Called IPV hotlines or referrals & $10(13)$ & \\
\hline $\begin{array}{l}\text { Changed or unlisted telephone } \\
\text { number }\end{array}$ & & $9(19)$ \\
\hline \multicolumn{3}{|c|}{$I P V=$ intimate partner violence; $W E B=$ Women's Evidence of Battering Scale. } \\
\hline \multicolumn{3}{|c|}{$\begin{array}{l}\text { Note: a positive finding for male IPV victimization was any positive response } \\
\text { on the IPV victimization scale and either lack of perpetration disclosure or evi- } \\
\text { dence of battering }(W E B>20) \text { on a sex-neutral version of the battering scale. }\end{array}$} \\
\hline \multicolumn{3}{|c|}{$\begin{array}{l}\text { Results available only for men who returned to the emergency department } \\
\text { for follow-up interviews at } 1 \text { week and/or } 3 \text { months after initial screening, } \\
\text { counseling, and referral to resources. }\end{array}$} \\
\hline
\end{tabular}

hospital emergency department, which limits generalizability. Only nonurgent patients were recruited; thus, we may have missed the more severe forms of IPV seen with major trauma. Although there was no indication of any safety concerns related to screening men 
for IPV based on observation during the emergency department visit self-report at 1 week or an increase in 911 telephone calls to their addresses, we were only able to follow up on $55 \%$ of male victims at 1 week. Also the study method of using 911 calls to their address can result in misclassification, because we did not track the 911 calls by individual, just by address. So there may have been undetected adverse events. IPV was self-reported and therefore subject to recall bias or unwillingness to disclose. There was no external validation of the actual levels and types of IPV, so the potential for classification error warrants caution when interpreting our results. Although we tried to use validated screening tools, IPV is best validated by partner report, and more work is needed to improve the sensitivity and specificity of screening tools for IPV in male patients in health care settings.

In conclusion, we found a cumulative risk of depressive and PTSD symptoms, suicidal ideation, and substance abuse to be associated with violence in the relationships of male urban emergency department patients. The identification of IPV risk in men as part of a health risk assessment provides opportunities for new targeted IPV interventions delivered outside the criminal justice setting. Such interventions must be guided by an understanding of the heterogeneity of male partner violence and co-occurring behavioral and mental health issues.

To read or post commentaries in response to this article, see it online at http://www.annfammed.org/cgi/content/full/7/1/47.

Key words: Male intimate partner violence; violence and mental health; behavioral health risks; preventive health screening; aggression; interpersonal relations; violence; health risk appraisal; health surveys

Submitted November 2, 2007; submitted, revised, July 2, 2008; accepted July 14, 2008.

Funding support: The data used in this study was collected with support from Centers for Disease Control and Prevention, R49 423113. Karin Rhodes, MD, MS, was supported by a grant from the National Institute of Mental Health, K23 MH64572; Debra Houry, MD, MPH, was supported by a grant from the National Institute of Mental Health, K23069375.

Acknowledgments: The authors wish to acknowledge Joanna Bisgaier, MSW, for help with manuscript preparation, James Wiley, PhD, for inspiration and conceptual clarity, and the many other people who have contributed to this project, particularly our research assistants, Robin Schultz Kemball, MPH, and Hadley Mintz, MPH, and the staff and patients of Grady Hospital Emergency Department.

\section{References}

1. Tjaden P, Thoennes N. Prevalence, Incidence, and Consequences of Violence Against Women: Findings From the National Violence Against Women Survey. Washington, DC: National Institute of Justice and Centers for Disease Control and Prevention; 1998.
2. Saltzman LE, Green YT, Marks JS, Thacker SB. Violence against women as a public health issue. Am J Prev Med. 2000;19(4):325-329.

3. Archer J. Sex differences in aggression between heterosexual partners: a meta-analytic review. Psychol Bull. 2000;126(5):651-680.

4. Cascardi M, Langhinrichsen J, Vivian D. Marital aggression: impact, injury, and health correlates for husbands and wives. Arch Intern Med. 1992;152(6):1178-1184.

5. Caetano R, Ramisetty-Mikler S, Field CA. Unidirectional and bi-directional intimate partner violence among White, Black, and Hispanic couples in the United States. Violence Vict. 2005;20(4):393-406.

6. Straus MA. The controversy over domestic violence by women: a methodological, theoretical, and sociology of science analysis. In: Arriaga XB, Oskamp S. Violence in Intimate Relationships. Thousand Oaks, CA: Sage Publications;1999.

7. Vivian D, Langhinrichsen-Rohling J. Are bi-directionally violent couples mutually victimized? A gender-sensitive comparison. Violence Vict. 1994;9(2):107-124.

8. Cunradi CB, Caetano R, Clark CL, Schafer J. Alcohol-related problems and intimate partner violence among White, Black, and Hispanic couples in the US. Alcohol Clin Exp Res. 1999;23(9):1492-1501.

9. Lipsky S, Caetano R, Craig A. Larkin. GL: Psychosocial and substance-use risk factors for intimate partner violence. Drug Alcohol Depend. 2004;78(1):39-47.

10. Bennett LW, Tolman RM, Rogalski CJ, Srinivasaraghavan J. Domestic abuse by male alcohol and drug addicts. Violence Vict. 1994;9(4):359-368.

11. Chase KA, O'Farrell TJ, Murphy CM, Fals-Stewart W, Murphy M. Factors associated with partner violence among female alcoholic patients and their male partners. J Stud Alcohol. 2003;64(1):137-149.

12. Chermack ST, Taylor SP. Alcohol and human physical aggression: pharmacological versus expectancy effects. J Stud Alcohol. 1995;56(4):449-456.

13. Collins JJ, Kroutil LA, Roland EJ, Moore-Gurrera M. Issues in the linkage of alcohol and domestic violence services. In: Galanter M, ed, Alcoholism and Violence. New York, NY: Plenum Press; 1997:387-405.

14. Danielson KK, Moffitt TE, Caspi A, Silva PA. Comorbidity between abuse of an adult and DSM-III-R mental disorders: evidence from an epidemiological study. Am J Psychiatry. 1998;155(1):131-133.

15. Jones AS, Gondolf EW. Time-varying risk factors for reassault among batterer program participants. J Fam Violence. 2001;16(4):345-359.

16. Leonard KE. Drinking patters and intoxication in marital violence: review, critique and future directions for research. In: US Department of Health and Human Services, ed. Research Monograph 24: Alcohol and Interpersonal Violence: Fostering Multidisciplinary Perspectives. Rockville, MD: National Institutes of Health; 1993:253-280.

17. O'Farrell TJ, Fals-Stewart W. Behavioral couples therapy for alcoholism and drug abuse. J Subst Abuse Treat. 2000;18(1):51-54.

18. O'Farrell TJ, Choquette KA, Cutter HS, et al. Cost-benefit and costeffectiveness analyses of behavioral marital therapy as an addition to outpatient alcoholism treatment. J Subst Abuse. 1996;8(2):145-166.

19. Campbell JC, Kub J, Belknap RA, Templin T. Predictors of depression in battered women. Violence Against Women. 1997;3(3):271-293.

20. Coid J, Petruckevitch A, Chung W, Richardson J, Morrey S, Feder G. Abusive experiences and psychiatric morbidity in women primary care attenders. Br J Psychiatry. 2003;183:332-339.

21. Stein MB. Kennedy C. Major depressive and post-traumatic stress disorder comorbidity in female victims of intimate partner violence. J Affect Disord. 2001;66(2-3):133-138.

22. Coker AL, Davis KE, Arias I, et al. Physical and mental health effects of intimate partner violence for men and women. Am J Prev Med. 2002;23(4):260-268.

23. O'Leary KD. Conjoint therapy for partners who engage in physically abusive behavior. In: Geffner R, Rosenbaum A, eds. Domestic Violence Offenders: Current Interventions, Research, and Implications for Policies and Standards. New York, NY: Haworth; 2001:145-164. 
24. Dutton MA, Mitchell B, Haywood Y. The emergency department as a violence prevention center. J Am Med Womens Assoc. 1996;51(3):92-95, 117.

25. Ernst AA. Intimate partner violence: steps for future generations. Ann Emerg Med. 2006;47(2):200-202.

26. U.S. Department of Health and Human Services. Healthy People 2010: Understanding and Improving Health. 2nd ed. Washington, DC: uS Government Printing Office; 2000.

27. Rhodes KV, Lauderdale DS, He T, Howes DS, Levinson W. "Between me and the computer": increased detection of intimate partner violence using a computer questionnaire. Ann Emerg Med. 2002;40(5):476-484.

28. MacMillan $\mathrm{HL}$, Wathen $\mathrm{CN}$, Jamieson $\mathrm{E}$, et al. Approaches to screening for intimate partner violence in health care settings: a randomized trial. JAMA. 2006;296(5):530-536.

29. Houry D, Kaslowe N, Kemball RS, et al. Does screening in the emergency department hurt or help victims of intimate partner violence? Ann Emerg Med. 2008;51(4):433-442.

30. Houry D, Kemball R, Rhodes KV, Kaslow NJ. Intimate partner violence and mental health symptoms in African American female emergency department patients. Am J Emerg Med. 2006;24(4): 444-450.

31. Heron SL, Thompson MP, Jackson E. Kaslowe. NJ: Do responses to an intimate partner violence screen predict scores on a comprehensive measure of intimate partner violence in low-income black women? Ann Emerg Med. 2003;42(4):483-491.

32. Rhodes KV, Khan Z. Validating a screen for IPV among male emergency department patients. Acad Emerg Med. 2005;12(5):46.

33. Rhodes KV, Lauderdale DS, Stocking CB, Howes DS, Roizen MF, Levinson W. Better health while you wait: a controlled trial of a computer-based intervention for screening and health promotion in the emergency department. Ann Emerg Med. 2001;37(3):284-291.

34. Beck AT, Steer RA, Brown GK. Manual for the Beck Depression Inventory-II. San Antonio, TX: Psychological Corporation; 1996.

35. Dozois DJ, Dobson KS, Ahnberg JL. A psychometric evaluation of the Beck Depression Inventory-II. Psychol Assess. 1998;10:83-89.

36. Foa EB, Riggs DS, Dancu CV, Rothbaum BO. Reliability and validity of a brief instrument for assessing post-traumatic stress disorder. J Trauma Stress. 1993:6:459-473.

37. Beck AT, Kovacs M, Weissman A. Assessment of suicidal intention: the Scale for Suicide Ideation. J Consult Clin Psychol. 1979;47(2):343-352.

38. Beck AT, Brown GK, Steer RA. Psychometric characteristics of the scale for suicide ideation with psychiatric outpatients. Behav Res Ther. 1997;35(11):1039-1046.

39. Ewing JA. Detecting alcoholism: the CAGE questionnaire. JAMA 1984;252(14):1905-1907.

40. Nilssen O, Cone H. Screening patients for alcohol problems in primary health care setting. Alcohol Health Res World. 1994;18(2):136-139.

41. Soderstrom CA, Smith GS, Kufera J, et al. The accuracy of the CAGE, the Brief Michigan Alcoholism Screening Test, the Alcohol Use Disorders Identification Test in screening trauma center patients for alcoholism. J Trauma. 1997;43(6):962-969.

42. Ernst AA, Nick TG, Weiss SJ, Houry D, Mills T. Domestic violence in an inner-city ED. Ann Emerg Med. 1997;30(2):190-197.

43. Lemon SC, Verhoek-Oftedahl W, Donnelly EF. Preventive healthcare use, smoking, and alcohol use among Rhode Island women experiencing intimate partner violence. J Womens Health Gend Based Med. 2002;11(6):555-562.

44. Guttman L. A new approach to factor analysis: the radex. In Lazars feld PF, ed. Mathematical Thinking in the Social Sciences. New York, NY: Free Press;1954
45. Felitti VJ, Anda RF, Nordenberg D, et al. The relationship of adult health status to childhood abuse and household dysfunction. Am J Prev Med. 1998;14(4):245-258.

46. Grisso JA, Schwarz DF, Hirschinger $N$, et al. Violent injuries among women in an urban area. N Engl J Med. 1999;341(25):1899-1905.

47. Hamberger KL, Potente T. Counseling Heterosexual Women Arrested for Domestic Violence: Implications for Theory and Practice in Domestic Partner Abuse. New York, NY: Springer; 1996.

48. Rosenberg HJ, Rosenberg SD, Wolford GL, Manganiello PD, Brunette MF, Boynton RA. The relationship between trauma, PTSD, and medical utilization in three high risk medical populations. Int J Psychiatry Med. 2000;30(3):247-259.

49. Swan SC, Gambone LJ, Fields AM, Sullivan TP, Snow DL. Women who use violence in intimate relationships: the role of anger, victimization, and symptoms of posttraumatic stress and depression. Violence Vict. 2005;20(3):267-285.

50. Dutton DG, Golant SK. The Batterer: A Psychological Profile. New York, NY: Basic Books; 1995.

51. El-Bassel N, Gilbert L, Witte S, et al. Intimate partner violence and substance abuse among minority women receiving care from an inner-city emergency department. Womens Health Issues. 2003;13(1):16-22.

52. Lipsky S, Caetano R, Field CA, Bazargan S. The role of alcohol use and depression in intimate partner violence among Black and Hispanic patients in an urban emergency department. Am J Drug Alcohol Abuse. 2005;31(2):225-242.

53. Goldberg WG, Tomlanovich MC. Domestic violence victims in the emergency department: new findings. JAMA. 1984;251(24):3259-3264

54. Mechem CC, Shofer FS, Reinhard SS, Horig S, Datner E. History of domestic violence among male patients presenting to an urban emergency department. Acad Emerg Med. 1999;6(8):786-791.

55. Mills LD, Mills TJ, Taliaferro E, Zimbler A, Smith D. The prevalence of female-tomale intimate partner violence in an urban emergency department. J Emerg Med. 2003;25(2):215-218.

56. Muelleman RL, Burgess P. Male victims of domestic violence and their history of perpetrating violence. Acad Emerg Med. 1998;5(9):869-870

57. Salber PR, Taliaferro E. Men and domestic violence. Acad Emerg Med. 1998;5(9):849-850.

58. Coben JH, Friedman DI. Health care use by perpetrators of domestic violence. J Emerg Med. 2002;22(3):313-317.

59. Pence E, Paymar M. Education Groups For Men Who Batter: The Duluth Model. New York, NY: Springer;1993.

60. Gondolf E. Evaluating programs for men who batter: problems and prospects. J Fam Violence. 1987;2(1):95-108.

61. Gondolf E. A comparison of four batterer intervention systems: do court referral, program length, and services matter? J Interpers Violence. 1999;14(1):41-61.

62. Babcock JC, Green CE, Robie C. Does batterer's treatment work? A meta-analytic review of domestic violence treatment. Clin Psychol Rev. 2004;23(8):1023-1053.

63. Feder L, Wilson DB. A meta-analytic review of court-mandated batterer intervention programs: can the courts affect abuser's behavior? J Exp Criminol. 2005;1:239-262.

64. Cavanaugh MM, Gelles RJ. The utility of male domestic violence offender typologies: new directions for research, policy and practice. J Interpers Violence. 2005;20(2):155-166.

65. Miller SL. Expanding the boundaries: toward a more inclusive and integrated study of intimate violence. Violence Vict. $1994 ; 9(2): 183-194$ 